\title{
NOTES
}

\section{Effects of Monomer Sequence Alignment on Properties of $p$-Hydroxybenzoic Acid/Poly(ethylene terephthalate) Copolyester}

\author{
Jun-ichi SuEnaga and Masashi Kinugawa* \\ Unitika Ltd., Tokyo Office, 3-4-4 Nihonbashi-Muromachi, Chuo-ku, Tokyo 103, Japan \\ *Unitika Ltd., R\&D center, 23 Kozakura, Uji-shi, Kyoto-fu 611, Japan
}

(Received September 3, 1992)

\begin{abstract}
KEY WORDS Liquid Crystal Polyester / Liquid Crystalline Polymer / New
Process / Monomer Sequence Alignment /
\end{abstract}

$P$-hydroxybenzoic acid (PHB)/poly(ethylene terephthalate) (PET) copolyester ${ }^{1}$ is a representative thermotropic liquid crystal polyester (LCP) which is classified into a semi-aromatic LCP. ${ }^{2}$ This PHB/PET copolyester (original LCP) has typical properties of LCPs, but, is not competitive with all-aromatic $\mathrm{LCPs}^{3}$ in mechanical and thermal properties. Original LCP has been proved to have blocky monomer sequence alignment. ${ }^{4-6}$ On the other hand, all-aromatic LCP has random monomer sequence alignment. ${ }^{7-9}$

We reported that the LCP synthesized by a new process (NP LCP) consisting of divided additions of $p$-acetoxybenzoic acid (APHB) to PET improves the properties of original LCP, and that the insoluble fraction of original LCP damages its properties qualitatively. ${ }^{10}$ The present research was carried out to inspect the relationship between insoluble fraction and properties quantitatively by analyzing the average sequence length of homopolymerized PHB in LCPs.

\section{EXPERIMENTAL}

Synthesis of PHB/PET Copolyester

a) Original LCP was synthesized by a twostep reaction reported by Jackson. ${ }^{1}$ In the first step, an acidolysis step, all of the PET and APHB monomer were heated up to $275^{\circ} \mathrm{C}$ quickly for an acidolysis reaction under nitrogen flow in a reactor. In this step, PET was cleaved to create copolyester fragments. In the second step, a condensation step, the pressure in the reactor was gradually decreased to 0.3 Torr to form the high molecular weight copolyester (original LCP).

b) NP LCP was synthesized by a new process consisting of divided additions of APHB to PET. At first, PET and half of the APHB were reacted by same procedure as a) to obtain a intermediate LCP which has PHB/PET molar ratio of $60 / 40$. This intermediate LCP and shorted APHB were reacted by a repeated same procedure as a) to yield NP LCP.

c) LCP with intermediate amount of insoluble fraction between original LCP and NP LCP was synthesized by the same procedure as b) except for reducing the stirring speed.

\section{Measurement of Insoluble Fraction}

Glinded LCP powder with a size of 100 mesh pass was dissolved in $1 / 1$ mixed solvent of phenol and tetrachloroethane at $150^{\circ} \mathrm{C}$. Insoluble fraction was separated by a centrifugal separator. 
Table I. LCPs synthesized under different conditions

\begin{tabular}{|c|c|c|c|c|c|}
\hline LCP & $\mathrm{LCP}^{-} 1^{\mathrm{b}}$ & LCP-2 & LCP-3 & LCP-4 & $\mathrm{LCP}-5^{\mathrm{c}}$ \\
\hline $\begin{array}{l}\text { Amount of the insoluble } \\
\text { fraction }^{a}(\%)\end{array}$ & 0 & 3 & 9 & 15 & 30 \\
\hline
\end{tabular}

${ }^{13} C N M R$

${ }^{13} \mathrm{C}$ NMR spectra was measured by Varian Model VXR-300 operating at $75 \mathrm{MHz}$. Solution for ${ }^{13} \mathrm{C}$ NMR analysis was prepared by dissolving powdered LCP in hot pentafluorophenol.

\section{Properties}

Representative properties of LCPs were measured under the ASTM standard (D-790 for flexural modulus and flexural strength, D-256 for Izod impact strength, D-648 for heat deflection temperature). LCPs melted at $290^{\circ} \mathrm{C}$ were injection-molded into a mold of $90^{\circ} \mathrm{C}$ to prepare the test pieces.

Melt viscosity was measured by a plungertype viscometer (Flow Tester CFT-500, Simazu Seisakusho) at $290^{\circ} \mathrm{C}, 1000 \mathrm{~s}^{-1}$ of shear rate.

\section{RESULTS AND DISCUSSION}

Table I shows five LCPs with various amount of insoluble fractions. LCP-5 with $30 \%$ of insoluble fraction is the original LCP, and LCP-1 without insoluble fraction is the NP LCP. LCP-2 to LCP-4 have the intermediate amount of insoluble fractions between original LCP and NP LCP.

Table II shows elemental analysis of LCP-5, LCP-1 and the insoluble fraction of LCP-5. These results show that there are no differences in compositions among them.

Carbon on PHB aromatic ring next to oxygen give informations of the monomer sequence alignment in ${ }^{13} \mathrm{C}$ NMR spectrum. ${ }^{11}$ As shown in Figure 1, peaks of 157-
Table II. Elemental analysis of LCP-1, LCP-5, and insoluble fraction of LCP-5

\begin{tabular}{lll}
\hline & C & H \\
\hline LCP-1 & 67.81 & 3.56 \\
LCP-5 & 67.68 & 3.56 \\
Insoluble fraction of LCP 5 & 67.92 & 3.49 \\
Calculated for PHB/PET $=80 / 20$ & 67.86 & 3.60 \\
\hline
\end{tabular}

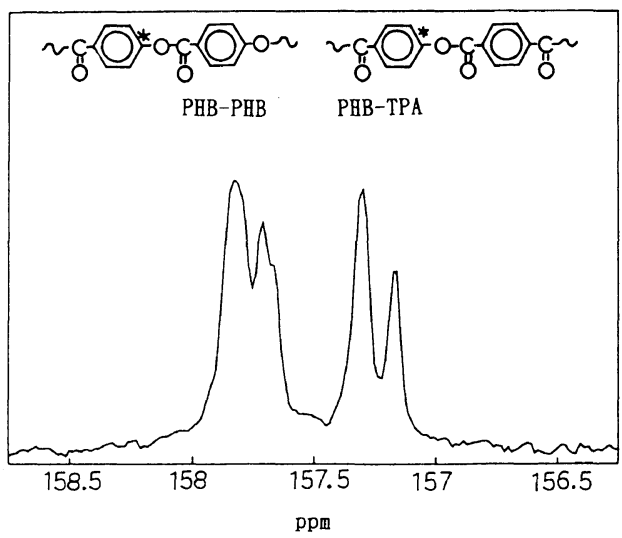

Figure 1. ${ }^{13} \mathrm{C}$ NMR spectrum of PHB/PET copolyester.

$157.5 \mathrm{ppm}$ were assigned to the carbon related to PHB-TPA bond, and peaks of 157.5$158 \mathrm{ppm}$ is assigned to the carbon related to PHB-PHB bond. Average sequence length of homopolymerized PHB $(A S L)$ can be presented by

$$
A S L=\frac{\text { PHB-PHB bond }}{\text { TPA-PHB bond }}+1
$$

Table III shows $A S L$ evaluated for LCP-5, LCP-1, and the insoluble fraction of LCP-5. LCP-1 is found to have much less blocky 
Table III. Average sequence length of homopolymerized PHB

\begin{tabular}{lccc}
\hline LCP-1 & LCP-5 & $\begin{array}{c}\text { Insoluble fraction } \\
\text { of LCP-5 }\end{array}$ \\
\hline $\begin{array}{c}\text { Average sequence length of } \\
\text { homopolymerized PHB }\end{array}$ & 2.3 & 3.1 & 4.5 \\
\hline
\end{tabular}

Table IV. Representative properties of LCPs having various amounts of insoluble fractions

\begin{tabular}{lcrrrrr}
\hline \multicolumn{1}{c}{ LCP } & Unit & LCP-1 & LCP-2 & LCP-3 & LCP-4 & LCP-5 \\
\hline Flexural strength & $\mathrm{kgf} \mathrm{cm}^{-2}$ & 1500 & 1420 & 1300 & 1230 & 1150 \\
Flexural modulus & $\mathrm{kgf} \mathrm{cm}^{-2}$ & 110000 & 102000 & 88000 & 76000 & 60000 \\
Izod impact strength & $\mathrm{kgf} \mathrm{cm} \mathrm{cm}^{-1}$ & 31 & 30 & 18 & 14 & 11 \\
Heat deflection temp & ${ }^{\circ} \mathrm{C}$ & 168 & 158 & 154 & 141 & 135 \\
Viscosity at $290^{\circ} \mathrm{C}$ & Poise & 1200 & 1300 & 1500 & 1600 & 1800 \\
\hline
\end{tabular}

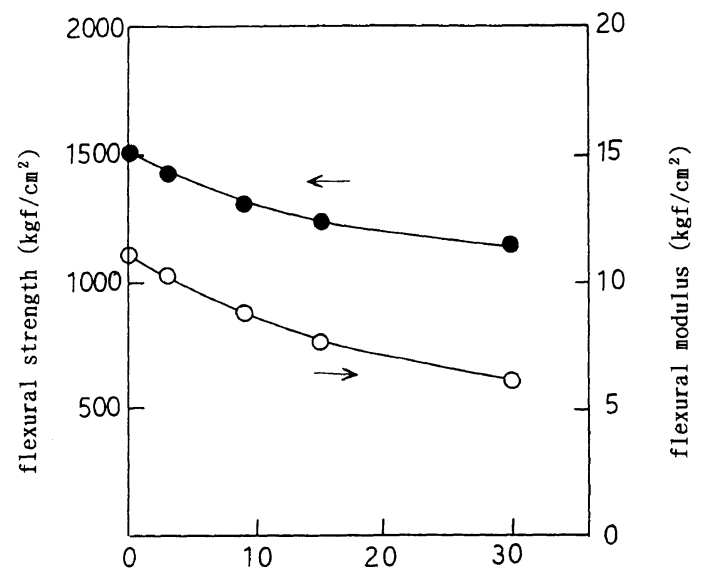

amount of insoluble fraction $(x)$

Figure 2. Effects of the insoluble fraction on flexural strength (- - ) and flexural modulus (-O-).

monomer sequence alignment than LCP-5. Since $A S L$ of 2 means an ideally alternative copolymer, LCP-1 with $A S L$ of 2.3 has almost random monomer sequence alignment. The insoluble fraction was found to have large ASL of 4.5.

Table IV shows representative properties of LCPs that have various amount of insoluble fractions. Figures 2 and 3 show that flexural properties and heat deflection temperature

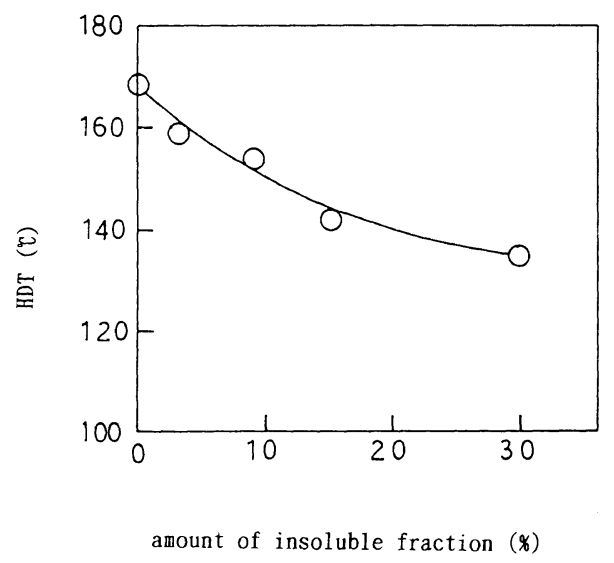

Figure 3. Effects of the insoluble fraction on heat deflection temperature.

(HDT) decreace along with the amount of insoluble fraction increasing, respectively. The insoluble fraction apparently damages mechanical and thermal properties of LCPs. PHB homopolymer blocks with $A S L$ larger than 4 is infusible and insoluble. ${ }^{12)}$ Insoluble fraction with $A S L$ of 4.5 should contain infusible homopolymer blocks. Since infusible PHB homopolymer blocks in LCPs disturb molecular orientation, mechanical properties are damaged by the insoluble fraction.

If cleaved PET remains as ethylene terephthalate unit in the LCP, $A S L$ would be 4 
because it has a composition of $80 / 20$ for PHB/PET. In LCP-5 with large $A S L$, the ethylene terephthalate unit must remain, at least in the insoluble fraction. Deformation of LCP-5 at lower temperature will be caused by this ethylene terephthalate unit.

\section{CONCLUSION}

The effects of insoluble fraction on properties of semi-aromatic LCP were investigated. Both the mechanical and thermal properties of semi-aromatic LCP decrease with the amount of insoluble fraction increase. Original LCP (LCP-5) with $30 \%$ of insouluble fraction, synthesized by Jackson's process, ${ }^{1}$ was found to have blocky monomer sequence alignment by ${ }^{13} \mathrm{C}$ NMR spectrum. On the other hand, NP LCP (LCP-1) without the insoluble fraction, synthesized by a new process, was found to have random monomer sequence alignment.

\section{REFERENCES}

1. W. J. Jackson and H. F. Kurfuss, J. Polym. Sci., Polym. Chem. Ed., 14, 2043 (1976).

2. J. Suenaga, Polym. News, 15, 201 (1990).

3. G. W. Calundann (Celanese), U.S. Patent 4161470 (1979)

4. V. A. Nicely, J. T. Dougherty, and L. W. Renfro, Macromolecules, 20, 573 (1987).

5. E. Joseph, G. L. Wilkes, and D. G. Baird, Polymer, 26, 689 (1985).

6. A. E. Zachariades and J. A. Logan, Polym. Eng. Sci., 23, 797 (1983).

7. J. Blackwell and G. A. Gutierrez, Polymer., 23, 671 (1982).

8. J. Blackwell, G. A. Gutierrez, and R. A. Chivers, $J$. Polym. Sci., Polym. Phys. Ed., 22, 1343 (1984).

9. T. S. Chung, Polym. Eng. Sci., 26, 901 (1986).

10. J. Suenaga, M. Kinugawa, and T. Imamura, Kobunshi Ronbunshu, 49, 493 (1992).

11. R. W. Lenz, J.-I. Jin, and K. A. Freichtinger, Polymer, 24, 327 (1983).

12. J.-I. Jin, S. Antoun, C. Ober, and R. W. Lenz, Br. Polym. J., 12, 132 (1980). 